\title{
Logistics impacts of student online shopping - evaluating delivery consolidation to halls of residence
}

\author{
Tom Cherrett', Janet Dickinson ${ }^{2}$ Fraser McLeod ${ }^{1}$, Jason Sit ${ }^{2}$, Gavin Bailey ${ }^{1}$, Gary \\ Whittle ${ }^{3}$ \\ ${ }^{1}$ University of Southampton, ${ }^{2}$ Bournemouth University, ${ }^{3}$ Meachers Global Logistics \\ Email: T.J.Cherrett@soton.ac.uk (corresponding author); JDickinson@bournemouth.ac.uk; \\ F.N.McLeod@soton.ac.uk; JSit@bournemouth.ac.uk; G.S.Bailey@soton.ac.uk; \\ gwhittle@meachersglobal.com
}

\begin{abstract}
Growth in online shopping has led to increased numbers of small delivery vehicles in urban areas leading to a range of negative externalities. Young people are significant generators of home deliveries and, when clustered in university halls of residence, can generate considerable freight traffic to one location. This paper explores the potential to consolidate these deliveries using an urban consolidation centre. Based on the case of Southampton, UK, data were compiled from three linked sources: a delivery audit of four halls of residence at the University of Southampton housing 5,050 residents; annual package receipt records from Southampton Solent University halls (2,294 residents); and an online shopping survey distributed to Southampton University students (486 responses). The results suggest that in cities with multiple higher education institutions (HEls), where in excess of 8,000 students live in halls, over 13,000 courier trips could be generated annually, delivering over $4,000 \mathrm{~m}^{3}$ of packages. These could be consolidated onto fewer than 300 vehicles for an annual service cost of approximately $£ 18$ per student, reducing congestion, parking infringements and improving air quality. Analysis indicated student acceptance of a consolidated parcel service but operational challenges would include enforcement, performance risk, finance and delivery speed.
\end{abstract}

Keywords E-Retail; Consolidation Centres; Home Delivery; halls of residence

\section{Introduction}

Freight transport makes up $16 \%$ of all road vehicle activity in UK cities, with lorries and vans performing $30 \%$ of their work load in urban areas (Department for Transport, 2015). Over the last ten years, van traffic has increased by almost a fifth while all other types have shown overall decreases (Browne et al., 2014; Department for Transport, 2015). A key reason for this is the growing demand for new ways of buying goods and fulfilling deliveries. Online shopping has grown from 3\% of total UK retail sales in 2007 to over $16.8 \%$ in 2015 (Cherrett et al., 2012; Retail Research, 2016) and, alongside this, just-in-time procurement has resulted in increasingly less-efficient small-package flows (Ofcom, 2015). A key generator of this freight activity are younger age groups who now do proportionally more of their shopping online than any other with $42 \%$ of $18-24$ year-olds declaring it as their major purchasing medium in 2014 (Statista, 2016). Given that around 27.5\% of the 1.4 million full-time UK undergraduate students live in halls during term-time (Higher Education Statistics Agency, 2015; Seock and Bailey, 2008), university student accommodation could be a significant freight generator in its own right. While studies have indicated a $\mathrm{CO}_{2}$ advantage for home delivery compared to the traditional high-street shopping trip (Edwards et al., 2010; Goodchild et al., 2016), most emissions accrue during the 'last mile' (Edwards et al., 2010; Wiese et al., 2015). This could be eroded further where large numbers of customers residing in the same complex, such as a university hall of residence, can all order independently with no penalty for generating separate deliveries. 
Urban Consolidation Centres (UCCs) have long been seen as a way for local authorities to alleviate the negative impacts of last-mile freight operations (Savelsbergh and Van Woensel, 2016) by grouping deliveries onto smaller numbers of less polluting vehicles. Results suggest that they have often failed to make the impact expected due to difficulties attracting clients and issues of longer term financial viability (Allen et al., 2012). Of interest in this research is whether a new market for UCCs exists in helping to better manage the movement of private deliveries to students living in halls of residence, particularly in cities where multiple higher education establishments exist.

With this in mind, we make three contributions in this paper: firstly, we quantify the scale of student e-retail activity through an audit of packages received across the halls of residence at the University of Southampton, UK, during the week after the 'Black Friday' retail event (27/11/15); secondly, we investigate the behaviour behind this activity through a structured questionnaire survey of students living in halls; finally, working with the operator of a UCC serving the city of Southampton, (Meachers Global Logistics), we use both studies and data from Southampton Solent University to propose how halls post could be consolidated and quantify the costs and issues associated with doing this via a UCC.

\section{Background}

\subsection{Online purchasing habits and impacts on logistics}

People are shopping and spending more online with the desire for convenience and monetary value (savings) resulting from longer working hours, less leisure time and/or lower disposable income; rising ownership of computers and mobile devices (e.g. smartphones and tablets) and improved internet connectivity (Mintel, 2015a, 2015b). Market surveys also indicate that young people, especially those aged between 18 and 34 years, make up a significant sector of online retail customers (ShopperVista, 2016) due to their preference for using the medium which fits with their recognised spur of the moment purchasing and 'live for today' attitudes (Passport, 2013, 2015; Mintel, 2015a, 2016). Online shopping continues to disrupt the business models and logistics of the retail sector and is turning physical retail stores into 'showrooms' where people browse and inspect goods but do not necessarily purchase (Wenig and London, 2014). Moreover, online shopping is also pushing retailers to introduce innovative services that are either free of charge or highly desirable to their online customers, such as fast delivery services (e.g. same-day delivery), subscription for unlimited delivery (e.g. Asos's Premier Delivery), click-and-collect services, self-service lockers in convenient locations, or flexible return procedures for items bought online (Mintel, 2015b). Being able to choose delivery slots with no minimum spend is also becoming a common expectation of online shoppers (Mintel, 2016).

The UK courier and express services market generated approximately $£ 9 b$ in revenue across 11,765 companies during 2015 (Key Note, 2015). With approximately 1.065 billion parcels delivered across the UK, of which an estimated 260 million were handled during November and December (IMRG, 2015), the impacts of home delivery on logistics and personal travel could be considerable but are not well understood. It has been suggested that general fragmentation in the retail sector resulting from retailers offering ever more service variants to customers could lead to more freight vehicle movements, particularly where crowd-sourced couriers are employed. In contrast, more delivery options and mechanisms made available to customers (particularly the potential for unattended delivery) might result in changes in travel behaviour and fewer personal car journeys being made (Visser et al., 2014). Problems experienced by customers with online retail have been largely related to delivery with $15 \%$ stating that no-one was in to receive the item when it arrived, $13 \%$ reporting delays in delivery and $3 \%$ having to make a collection from a courier's depot in response to a failed first-time delivery (Eurobarometer, 2013; Morganti and Dablanc, 2014). 


\subsection{Urban Consolidation Centres and their role in reducing last-mile delivery impacts}

Urban Consolidation Centres (UCCs) are secure warehouse or cross-dock facilities which allow multiple deliveries of consignments destined for various customers within an urban area to be consolidated together into fewer vehicles for the final leg of their journey (Browne et al., 2005). They have been in operation since the mid-1970s across Europe with over 114 schemes having been identified across the retail, office, residential and construction sectors (Allen et al., 2012). UCCs can be divided into three basic types (Allen et al., 2012; Triantafyllou et al., 2015): i) UCCs serving all or part of an urban area (often instigated by a local authority and associated with the supply of retail and office products to specific urban districts suffering from transport-related problems); ii) UCCs serving single-landlord sites (typically managing retail products and supplies for airports, shopping centres and hospitals where minimising the need for on-site storage to maximise retail/operational space is of primary importance). In this case, the UCC can either be 'suggested' by the landlord, where an incentive of additional storage space and services is given to those retailers signing up to use the UCC or 'demanded', as a condition of the rental contract (e.g. London Heathrow) (Browne et al., 2005); and iii) Construction UCCs designed specifically to handle construction materials.

Where they have been instigated by a local authority, a key motivation has been to reduce the numbers of freight vehicles operating within the urban area (Browne et al., 2005) and reported reductions in vehicle trips and kilometres travelled have been between $60 \%$ and $80 \%$, with associated reductions in greenhouse gas emissions of between $25 \%$ to $80 \%$ (ibid). One of the more significant schemes was introduced in Japan (1994) where 36 individual logistics providers signed up to a public-private partnership with the national and regional government in Fukuoka City, using a UCC to serve the central business district (CBD). The regional government also enhanced parking facilities for freight vehicles which resulted in a $65 \%$ reduction in the number of freight vehicles in the CBD and $87 \%$ in their associated $\mathrm{kms}$ travelled (OECD, 2003). UCCs also improve load consolidation and the ability to reduce the numbers of freight vehicles over the last-mile has had positive effects in reducing the space and time taken up by delivery vehicles at the kerbside (Boudouin, 2006; Browne et al., 2005; Gonzalez-Feliu and Morana, 2010; WSP, 2008 in Allen et al., 2012).

A major issue has been their long-term financial viability with some believing that they may only be suited to specific controlled environments, or 'captive markets' where users are compelled to co-operate, such as construction sites or where strict landlord-tenant relationships exist (Kin et al., 2016; van Rooijen and Quak, 2010; Zunder and Marinov, 2011; Allen et al., 2012) as is the case with university accommodation. The additional link added into the supply chain is viewed as an additional cost (McKinnon, 1998; Marcucci and Danielis, 2007), and many UCCs have only materialised and continue to operate with the aid of public subsidy (Verlinde et al., 2012; Browne et al., 2005). Despite this, with local, national and European governments particularly concerned about vehicle emissions and air quality standards, UCCs are seen as a major aid to achieving sustainable urban freight logistics in the long term (Savelsbergh and Van Woensel, 2016).

\subsection{Higher Education Institutions - a potential market for UCCs?}

The majority of UCC trials have been focussed on retail operations (Browne et al., 2005). Although other sectors have been highlighted as applicable (e.g. office developments, service organisations, leisure complexes), little attention has been paid to the scope for large municipal organisations (higher education institutions, hospitals, local authorities) to reduce their logistics footprints by adopting consolidated deliveries. Higher Education Institutions (HEls) are major centres of commerce in cities across the UK and often make up one of the 
largest regional employers (Wells et al., 2009). In 2013/14, 2,299,355 students registered across 162 UK HEls (1,759,915 undergraduates and 539,440 postgraduates), overseen by some 395,780 academic and non-academic staff (Higher Education Statistics Agency, 2015). The total income across the sector was $£ 30.7 \mathrm{bn}$ which would position it fourth in the FTSE 350 top revenue generators (Association of University Directors of Estates, 2014). Investment in the HEl estate increased by $9 \%$ to over £2bn in 2013/14 (ibid) and research has suggested that a HEI with 5000 staff can generate in excess of 160 freight vehicles per day (Zunder et al., 2014) across its various teaching, research and administrative functions.

Of interest in this paper is the specific impact of personal deliveries on HEI residencies (or 'halls') which is an under researched area. Traditionally, first year undergraduates take a place in a hall of residence and these often large, multi-occupancy developments form a key element of the estates of most HEls in the UK (McLeod et al., 2016). Given that many UK HEls have student populations in excess of 20,000 , this can result in a cohort of around 4,000 to 8,000 students living in such complexes during term time. During the 2013/14 academic year, there were thought to be around 385,000 students living in halls at UK HEls (Higher Education Statistics Agency, 2015) and given their propensity to order online (Statista, 2016; Seock and Bailey, 2008), halls of residence could be an ideal candidate for consolidated deliveries via a UCC.

The model most aligned to this would be a centralised UCC (Torbianelli, 2009) serving a 'single site', where the HEl acts as the landlord, 'demanding' that couriers deliver into the facility (Browne et al., 2005; Panero and Lopez, 2011), and that students use it as a default address when ordering online. In terms of a viable operating model, the UCC would be an existing commercial facility operated by a third-party servicing a range of clients which was the case in this research. In this sense, HEls would become another client serviced by the UCC operator. The costs of the UCC service could be covered in the annual halls fee levied to the students or potentially via savings in the university's human resource costs needed to manage package receipt. With couriers taking deliveries into the UCC, consolidated loads could be made and delivery times negotiated with halls to suit reception staff, particularly where residencies do not operate a 24-hour reception. The off-site management of packages could free up a hall's reception space and reduce the disruption associated with receiving multiple deliveries randomly throughout the day, leading to improvements in staff planning and productivity at residencies. Other HEI drivers include managing increased van traffic around halls and the associated health and safety concerns.

Student acceptance of a consolidated delivery service is critical to its long-term success and a concern is the rise in same-day delivery services which, if popular, could greatly hinder uptake. Educating students in the transport ramifications of e-retail transactions could be an important component in this regard as student-led sustainability programmes at HEls have proven successful in changing attitudes (e.g. the student-led 'Blackout' energy reduction campaign at the University of Southampton, (UOS, 2016)). While there has been some work on young people's online retail behaviours (Passport, 2013; 2015; ShopperVista, 2016), there is currently relatively little known about young people's delivery preferences, a key factor influencing their shopping habits. Potential success also hinges on logistic providers' and retailers' support for the UCC concept which has implications for responsibility of items in transit, especially when delivery options require a signature.

With the pressure on HEls to improve their environmental and ethical performance (People and Planet, 2015; Universities UK Efficiency and Modernisation Task Group, 2011), along with the need for local authorities to reduce $\mathrm{CO}_{2}$ from logistics activity in urban areas, there is an opportunity to investigate how UCCs could be used for mutual gains. The true extent of parcel delivery to HEI halls and the opportunity for consolidation is not well understood and was the motivation behind this research. 


\subsection{Impact of trust and risk in online shopping and the introduction of UCCs}

Online shopping behaviour is mediated in various respects with the absence of face-to-face contact presenting a number of fundamental transaction concerns related to trust, responsibility for delivery, speed and cost of delivery. Lack of trust is a fundamental reason why customers fail to follow through online purchases (Kim and Park, 2013) and this can be extended to third parties involved in the delivery. Trust is typically analysed in terms of honesty, benevolence, competence and predictability (McKnight et al., 1998). In online transactions, honesty reflects the belief that a company will fulfil its promises to deliver the item ordered online (Kim and Park, 2013). Benevolence is the belief that the company actions do not compromise the customer's wellbeing (ibid). Competence refers to the trusted party having the relevant skills and ability to undertake a specific task (Flavián et al., 2006; Vidotto et al., 2012). Competence therefore reflects whether the HEI and the UCC, in the opinion of the shopper, have the financial, technical and human resources (Flavián et al., 2006) necessary to operate a consolidated delivery service. Predictability reflects the customer's trust in a delivery arriving as forecast by the vendor (Vidotto et al., 2012).

Perceived risk in the transaction is another important component of online purchase decision making (Chaparro-Peláez et al., 2016) which has mostly been analysed in relation to payments, sharing personal information, product satisfaction and delivery concerns. If a purchase is considered low risk, for example due to low cost, then risk can be largely ignored. Risk in online retail is therefore related to product characteristics with price and degree of involvement needed by the customer in the product evaluation increasing purchase risk (Sinha and Singh, 2014).

There are conflicting findings about delivery risk: Chaparro-Peláez et al. (2016) found delivery risk to be less of a barrier to online retail compared to other risks; however, Ofcom (2015) found $45 \%$ of online customers had concerns about deliveries. A consolidated delivery service is likely to add an additional performance risk (Shin et al., 2016) though this is focused on cost and delivery speed (Ofcom, 2015). Speedier deliveries increase logistics costs and have implications for profit margins (Hua et al., 2010); however, Ofcom (2015) found that $60 \%$ of customers did not want to pay for upgraded services. It was also found that customers liked delivery notifications and tracking (ibid) which may be compromised by a consolidated parcel service.

\section{Methodology}

To investigate the impact of personal deliveries at HEI halls of residence and the scope for a consolidated delivery service using a UCC, data from the University of Southampton and Southampton Solent University were used. Southampton is a city on the south coast of the UK with a population of around 250,000 and is home to two universities, both situated within the central urban area. The University of Southampton is situated towards the northern end of the city, around $4 \mathrm{~km}$ from the city centre and has eight halls of residence (Figure 1 ), accommodating 6,592 students from a total student population of just under 25,000. Southampton Solent University is located in the city centre and has 6 halls, accommodating 2,294 students, out of a student population of more than 19,000, although many study parttime and live locally. All first year students are guaranteed a place in a hall subject to terms and conditions.

To investigate the impact of personal deliveries at halls of residence and the scope for a consolidated delivery service using a UCC, data were used through three linked activities: 


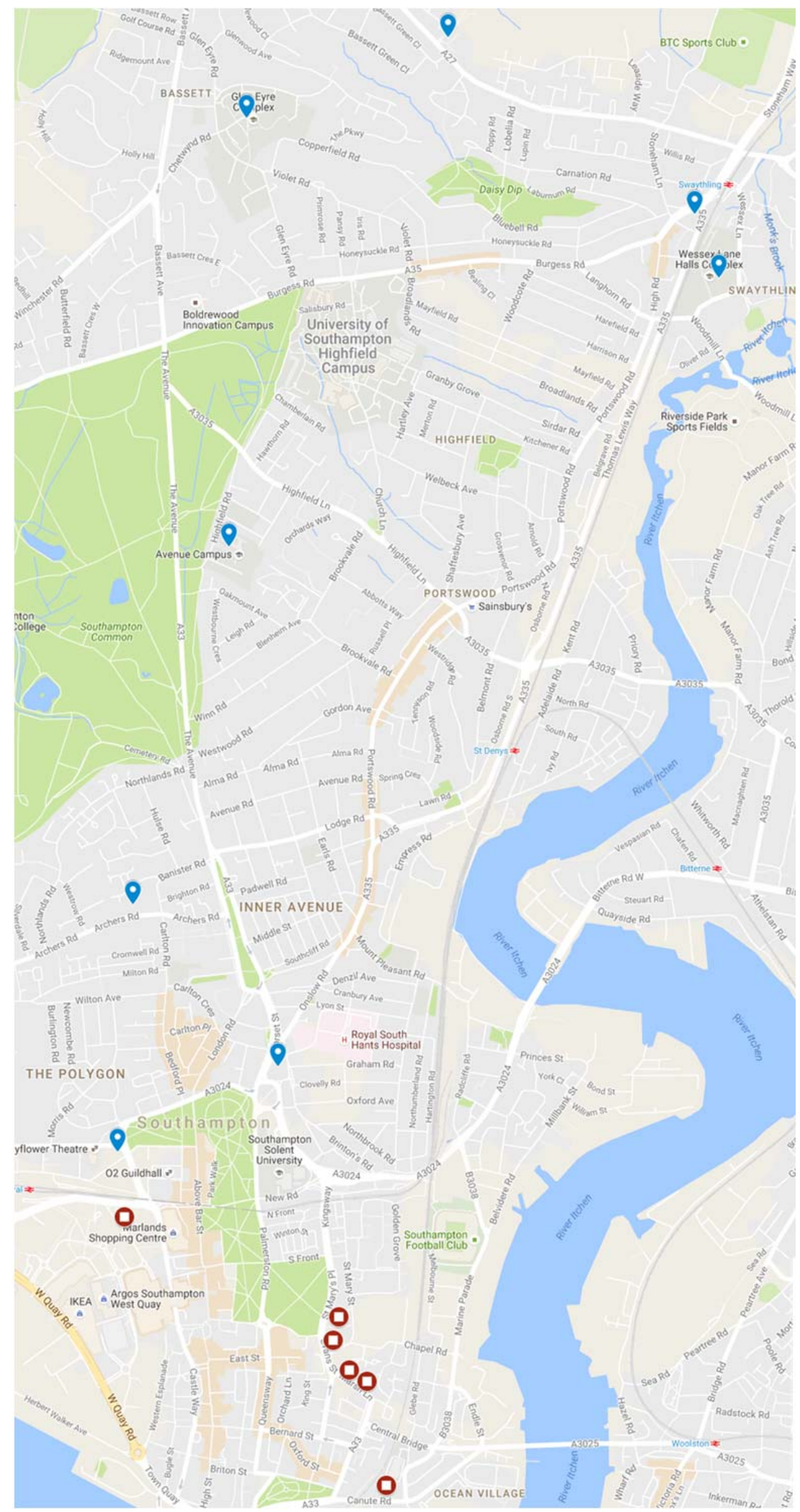

Figure 1. Locations of university halls of residence in Southampton

(Key: Pin =University of Southampton; Circle = Southampton Solent University) 


\subsection{Halls delivery audit}

Using four of the eight halls of residence at the University of Southampton, a 5-day delivery and service activity audit was undertaken to coincide with the week immediately following the Black Friday retail event, $27^{\text {th }}$ November 2015, (Saturday 28/11/15 - Friday 4/12/15) using surveyors stationed in the reception areas of each hall of residence between 09:00 and 17:00. Originating in the United States and falling on the day after the Thanksgiving holiday, Black Friday marks the start of the Christmas shopping season (Thomas and Peters, 2011) and in 2016 generated around US $\$ 3.3$ billion of online sales in the U.S., up $21.6 \%$ compared with the same day in 2015 (Rao, 2016; Veiga, 2016). It has also become popular in recent years as a major retail sales event in the UK, with many retailers extending the sales period over several days.

Surveys comprised observations of deliveries and a brief interview with delivery drivers and followed the standard audit procedure set down for undertaking delivery and service plans (Transport for London, 2016). The data recorded included arrival and departure times of couriers, the vehicle origin point, number of drops on the round and the next drop point in the sequence, the number and sizes of packages delivered, whether any deliveries were subject to time window constraints and the vehicle details (vehicle type and registration plate). Recording the latter allowed subsequent analysis of how many different vehicles were used by the main carriers to service the halls. A small number of deliveries were made at other times of day (e.g. shortly before 9am or shortly after $5 \mathrm{pm}$ ) some of which were noted by reception staff and reported to the returning surveyor the following day.

Goods-in data were also obtained from Southampton Solent University for five of their six halls using their parcel receipt software, covering a period from mid-September 2015 to midJuly 2016 (few packages for students would be expected during the summer vacation). This provided similar data to that obtained via the delivery and service audit, but with no vehicle details recorded, and allowed a more detailed investigation of seasonal trends in package receipt. These audits were used to quantify the extent of freight vehicle activity at halls, specifically related to student purchasing during peak and off-peak periods and the types of delivery service used. The seasonal trends observed from Southampton Solent University were also assumed for the University of Southampton and data were also extrapolated to consider the halls that were not surveyed, based on student numbers.

\subsection{Halls of residence online shopping survey}

An online survey was developed for distribution to students residing in halls. This was divided into sections covering: current online retail and delivery practices; opinions on a consolidated delivery service to halls; online retail habits during the 'Black Friday' sales week which took place the week prior to the survey distribution; and personal information.

In order to understand current online retail and delivery practices, respondents were asked to indicate the frequency of products ordered (based on product categories from Mintel (2015c)) for delivery to halls on an 8-point scale from 'never' to 'more than once per week' and the frequency of the delivery options chosen. This was followed by a series of Likerttype questions ('strongly agree' to 'strongly disagree' on a 5-point scale) addressing attitudes towards delivery options which focused on time, cost and convenience. The week following Black Friday was chosen as the focus, being the busiest online retail period of the year and for ease of recalling actual purchases made over the previous 7 days.

To explore the scope for reducing deliveries to halls, the concept of a consolidated delivery service was explained as follows: "One concept designed to reduce the amount of delivery vehicles visiting our halls of residence each day is to have a local warehouse act as the default delivery address which you would use when placing orders with non-food retailers. The warehouse would consolidate all the parcels destined for each hall and deliver them at a set time each day on one vehicle." Respondents were then asked to complete a series of 
Likert-type questions ('strongly agree' to 'strongly disagree' on a 5-point scale) related to their views on this concept. These focused on trust, responsibility for goods, speed and cost of delivery, and one question on environmental concerns.

The trust statements focused on the 'competence' component of trust and were adapted from the scale developed by Flavián et al. (2006). In terms of responsibility for goods, questioning focused on concerns about who would be liable for any damage or losses once goods had been signed over to the UCC from the courier. Three items focused on speed of receipt (which is also aligned with the predictability aspect of trust) and the time critical aspects of delivery. An item measuring 'present hedonistic' tendency was derived from Zimbardo's time perspective inventory ('I find myself getting swept up in the excitement of the moment'). This relates to hedonistic patterns of consumption identified among young people (Stanes et al., 2015). Two items focused on a combination of speed and cost as cost is often relative to the speed of delivery options. The personal information section asked for data on gender, fee status (home/EU and international students) and hall of residence (to indicate location). Age data were also collected, however, given halls of residence are typically for first year students there was little variation in age so this was not considered further in the analysis.

The questionnaire was distributed online during the first two weeks of December 2015 following Black Friday on $27^{\text {th }}$ November 2015. Distribution was via an email database of all students residing in halls of residence at the University of Southampton $(n=6,592)$ with 486 questionnaires returned of which 405 (6.1\%) were completed in full and considered for analysis. Women were over represented in the sample $(60 \%)$ which may reflect a gender bias towards completing a questionnaire about shopping and the sample included $75 \%$ home/EU students and $25 \%$ international students defined by fee status.

\subsection{UCC halls post service evaluation}

The final part of the methodology involved using the goods-in data from Southampton Solent University and knowledge gained from the questionnaire on student preferences to determine how a halls post consolidation service operating out of an existing UCC in Southampton would function. The analysis was also informed by working with the operator (Meachers Global Logistics) to quantify the likely costs, strengths, weaknesses, opportunities and threats.

\section{Results - Halls delivery audit}

The halls delivery audit at the University of Southampton gave a first insight into the scale of personal delivery activity at halls and the associated problems faced by reception staff in managing it. The parcel delivery and management system in the halls comprised the following elements:

- Deliveries were made by couriers to the hall's reception desks which were manned 24 hours a day. Some of the smaller halls did not have their own reception point and in these cases, their post was diverted to a neighbouring hall.

- Parcels were only accepted if the named recipient was resident at the hall. This involved checking the consignee on a computer system and logging accepted items. This process proved time-consuming when large consignments were delivered with couriers having to wait for each individual item to be checked.

- Parcels were kept in a storage area behind the reception desk.

- An automated email was sent by the computer system at 17:00 each day to inform students that the reception team were holding a parcel for them. The University policy was not to release any parcel in advance of this email having been sent. (N.B. Students may have already been informed of the delivery by the courier before this point through the couriers parcel tracking service). 


\subsection{Numbers of observed courier visits}

Across the four main halls of residence at the University of Southampton, serving a total of 5,050 residents, 275 freight vehicle visits were observed over the 6 day survey delivering packages for students with the largest hall receiving between 14 and 18 visits daily (Figure 2). Saturday was the least busy day (34 visits), while weekdays saw a fairly even spread of between 45 and 51 visits in total across all four sites. In many cases, the same courier company and the same driver were observed visiting the same hall daily and occasionally, twice on the same day. Carriers that were regularly observed (number of visits across the four halls in brackets) were: Yodel (29), DPD (26), Royal Mail (24), DHL (23), Hermes (20), Parcelforce (19), UPS (19), Amazon (16), Interlink (14), DX (13), with a total of 30 different logistics companies observed making parcel deliveries to the halls during the survey. From the vehicle registration plate analysis, Amazon used the most vehicles (9), followed by Yodel (7), Hermes (6), Interlink (6), Parcelforce (5), Royal Mail (5), UK Mail (5), with other carriers using fewer vehicles.

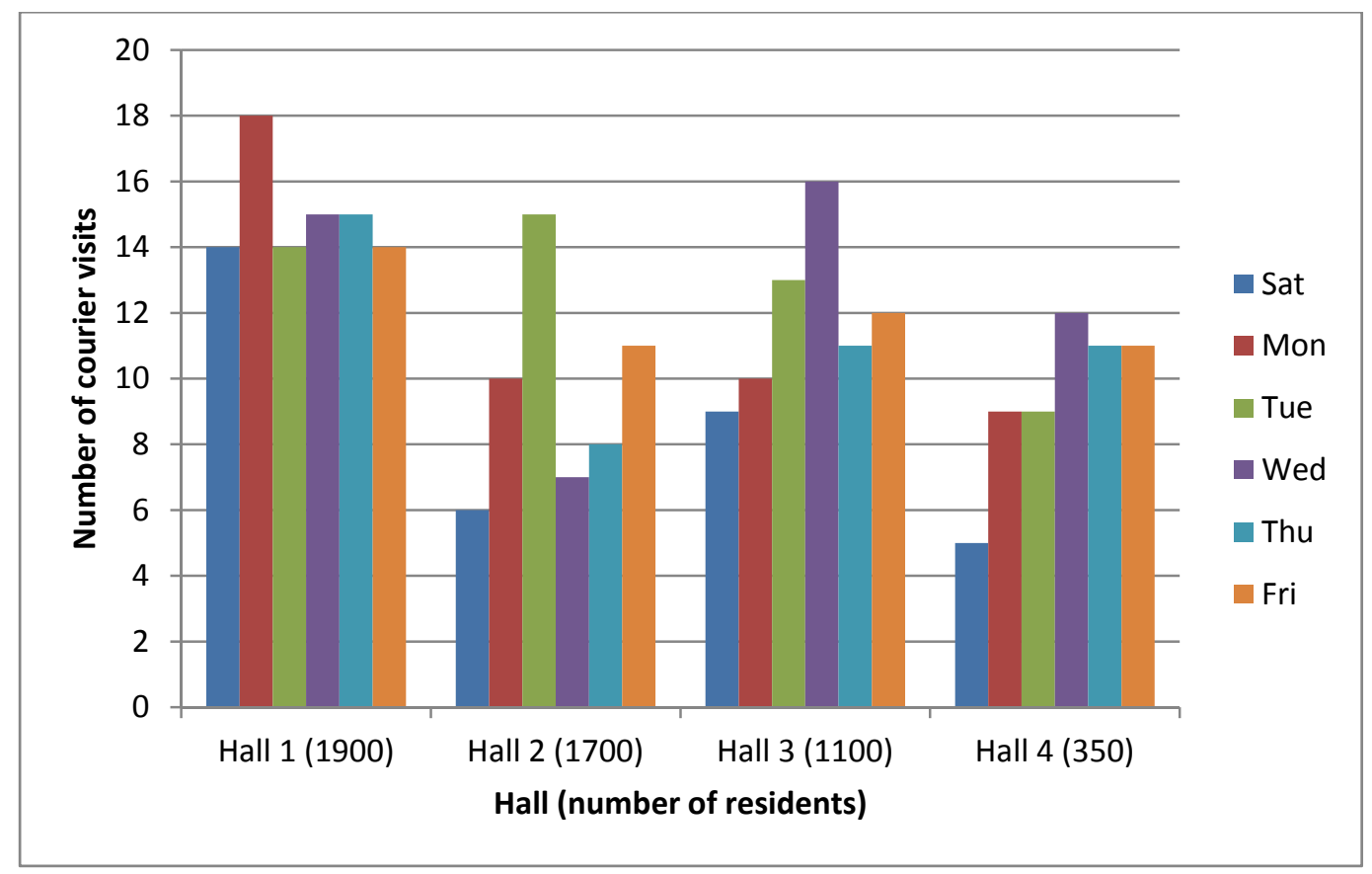

Figure 2. Number of courier visits observed at four University of Southampton halls of residence between Saturday 28/11/15 - Friday 4/12/15, 09:00 to 17:00. 


\subsection{Delivery times and durations}

When looking at the distribution of vehicle arrivals during the day, couriers were observed arriving at each hall throughout the main survey period (9am to $5 \mathrm{pm}$ ), but particularly between the hours of 09:00 and 13:00 (Figure 3). At the largest hall (Hall 1; 1,900 residents), there were approximately the same numbers of visits before $1 \mathrm{pm}$ as after, while at the other three halls, there were around twice as many deliveries before $1 \mathrm{pm}$ as after. One of the main advantages of adopting a consolidated delivery service for halls post would be to move away from this continuous stream of deliveries to a single one at a pre-specified time, allowing better staff time management.

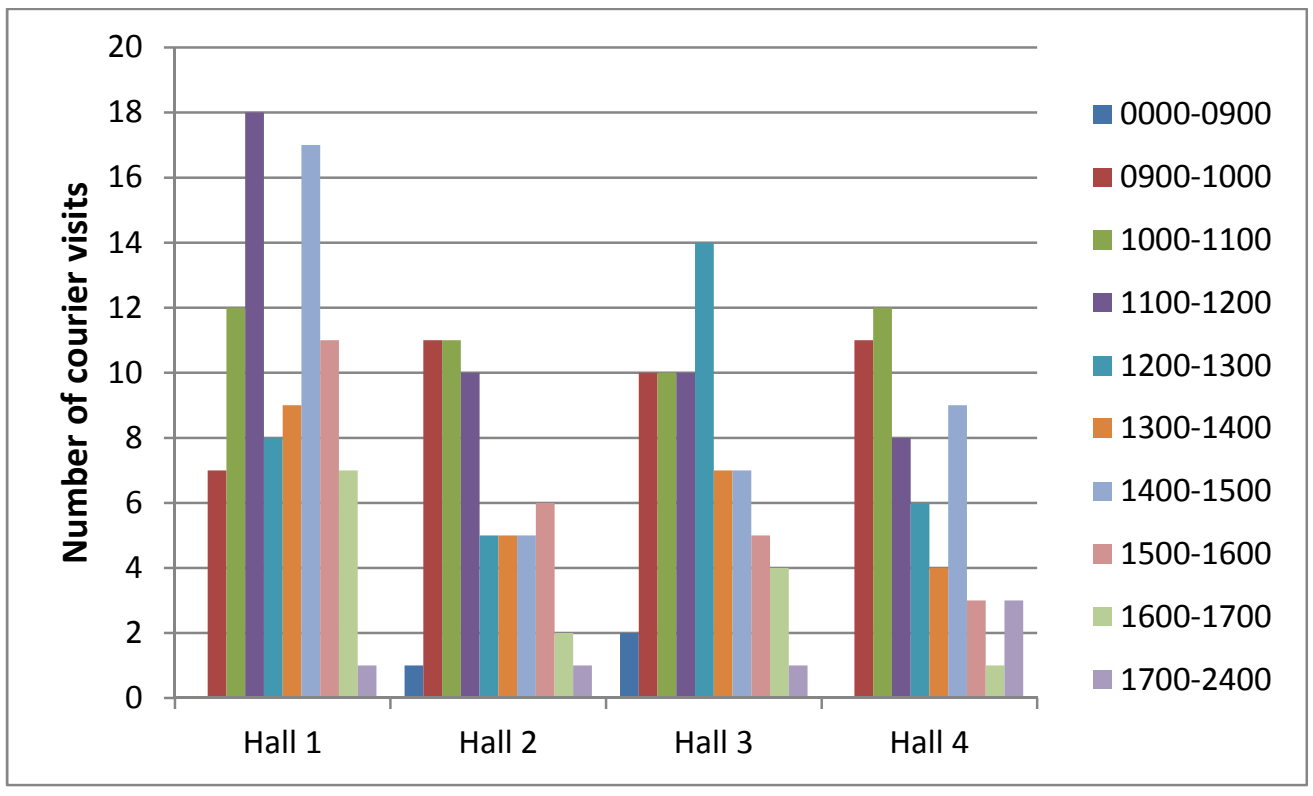

Figure 3. Observed courier visits to University of Southampton halls of residence by time interval (Saturday 28/11/15 - Friday 4/12/15, 09:00 to 17:00).

The amount of time spent by couriers at the hall reception points was typically quite short, with the mean observed dwell time being between 4 and 6.5 minutes (Figure 4) with no issues associated with access impacting on dwell time being observed at any of the locations. When looking at the delivery statistics of the most frequently observed carriers, Amazon showed the greatest standard deviation in dwell time, highlighting the time needed to book in large consignments (Table 1). Operating practice was observed to differ between logistics companies with some merely arriving and dropping with no waiting or receipting while others handling larger numbers of packages waited for up to 65 minutes in one instance while packages were individually checked in. A consolidated service would aim to relocate this receipting activity to the UCC where the halls receipt system would be used so freeing up reception staff for other duties. 


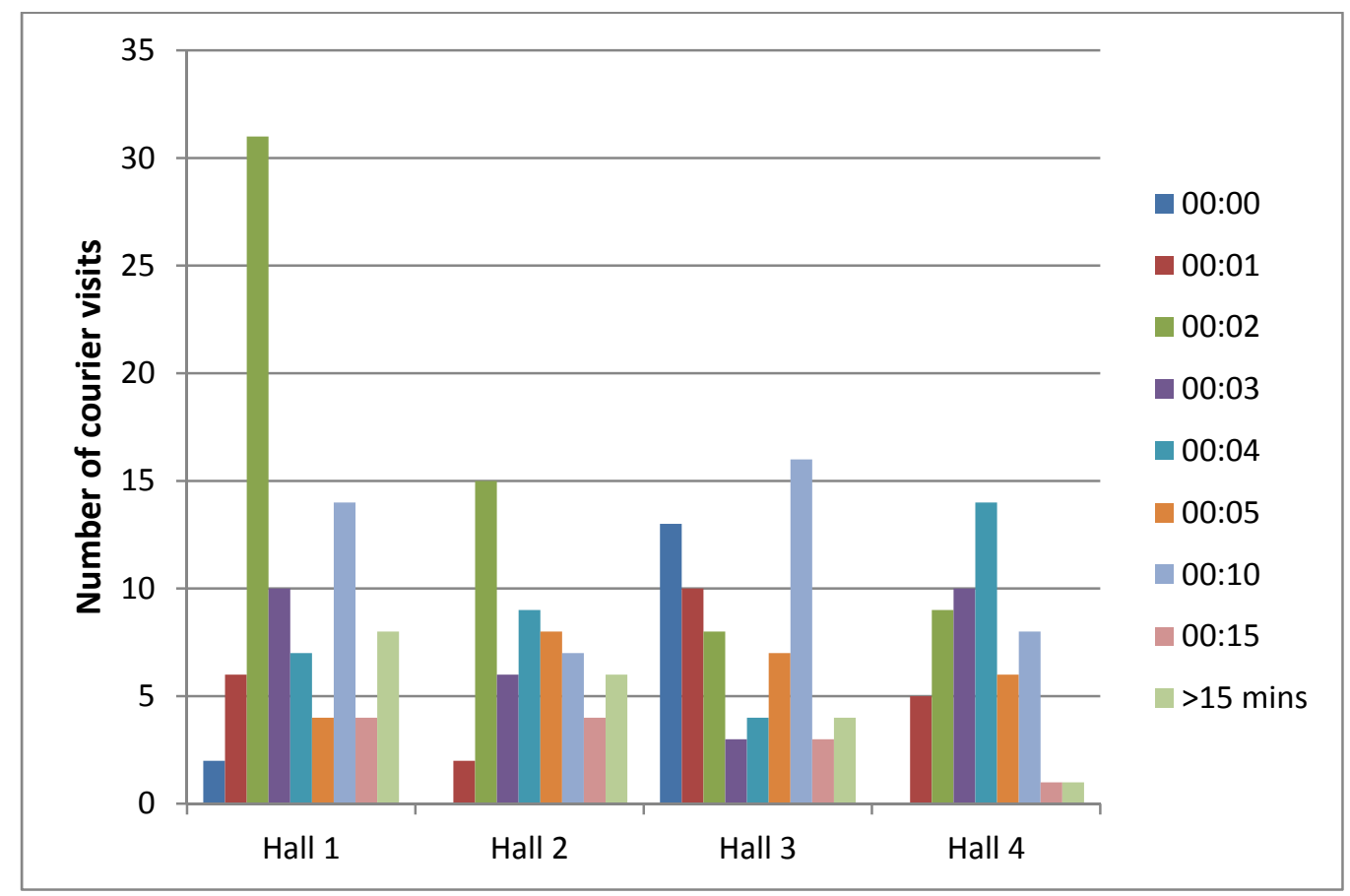

Figure 4. Frequency plot by duration of courier visit (mins) at University of Southampton halls of residence (Saturday 28/11/15 - Friday 4/12/15, 09:00 to 17:00).

Table 1. Observed activity of the top four logistics providers visiting University of Southampton halls of residence (Saturday 28/11/15 - Friday 4/12/15, 09:00 to 17:00).

\begin{tabular}{llllll}
\hline $\begin{array}{l}\text { Hall } \\
\text { (\#residents) }\end{array}$ & $\begin{array}{l}\text { Hall 1 } \\
\mathbf{( 1 , 9 0 0 )}\end{array}$ & $\begin{array}{l}\text { Hall 2 } \\
\mathbf{( 1 , 7 0 0 )}\end{array}$ & $\begin{array}{l}\text { Hall 3 } \\
\mathbf{( 1 , 1 0 0 )}\end{array}$ & $\begin{array}{l}\text { Hall 4 } \\
\mathbf{( 3 5 0 )}\end{array}$ \\
\hline \multirow{4}{*}{ Royal Mail } & \#packages & 659 & 85 & 49 & 41 \\
& \#visits & 7 & 6 & 5 & 6 \\
& mean dwell time & $08: 43$ & $11: 20$ & $07: 12$ & $05: 00$ \\
& st.dev. dwell time & $04: 04$ & $05: 43$ & $05: 24$ & $02: 29$ \\
\hline \multirow{4}{*}{ Hermes } & \#packages & 209 & 206 & 104 & 37 \\
& \#visits & 6 & 5 & 6 & 5 \\
& mean dwell time & $02: 50$ & $10: 48$ & $09: 20$ & $07: 00$ \\
& st.dev. dwell time & $02: 02$ & $05: 46$ & $05: 10$ & $04: 34$ \\
\hline \multirow{4}{*}{ Amazon } & \#packages & 247 & 48 & 165 & 47 \\
& \#visits & 7 & 6 & 7 & 2 \\
& mean dwell time & $24: 50$ & $15: 20$ & $10: 24$ & $15: 00$ \\
& st.dev. dwell time & $23: 08$ & $12: 41$ & $07: 37$ & $10: 36$ \\
\hline \multirow{5}{*}{ DPD } & \#packages & 77 & 38 & 50 & 21 \\
& \#visits & 7 & 6 & 6 & 7 \\
& mean dwell time & $05: 43$ & $03: 10$ & $05: 30$ & $03: 26$ \\
& st.dev. dwell time & $04: 37$ & $01: 20$ & $05: 53$ & $01: 54$ \\
\hline
\end{tabular}

Note: st. dev. = standard deviation 


\subsection{Number and volume of packages delivered}

In order to determine how halls post could be consolidated and handled via a consolidation centre, it was necessary to classify the sizes and types of packages received, and to understand how delivery volumes would vary during peak and off-peak periods. Observations of the package holding areas at each of the halls along with dialogue with the reception staff and halls managers derived a package and bag classification system to be used by the surveyors to categorise individual deliveries as they were received during the activity audit. These were:

\section{Bags}

- Small $=320 \mathrm{~mm} \times 240 \mathrm{~mm} \times 100 \mathrm{~mm}=0.00768 \mathrm{~m}^{3}$

- Medium $=440 \times 320 \times 150 \quad=0.02112 \mathrm{~m}^{3}$

- Large $=500 \times 420 \times 200 \quad=0.042 \mathrm{~m}^{3}$

\section{Boxes}

- Small $=305 \mathrm{~mm} \times 305 \mathrm{~mm} \times 305 \mathrm{~mm}=0.028373 \mathrm{~m}^{3}$

- Medium $=406 \times 406 \times 406 \quad=0.066923 \mathrm{~m}^{3}$

- Large $=510 \times 510 \times 510 \quad=0.132651 \mathrm{~m}^{3}$

Numbers of packages delivered during the survey week were counted and volumes estimated based on the above categorisation. A total of 3,504 parcels (bags or boxes) were delivered across the four sites during the survey period (Figure 5).

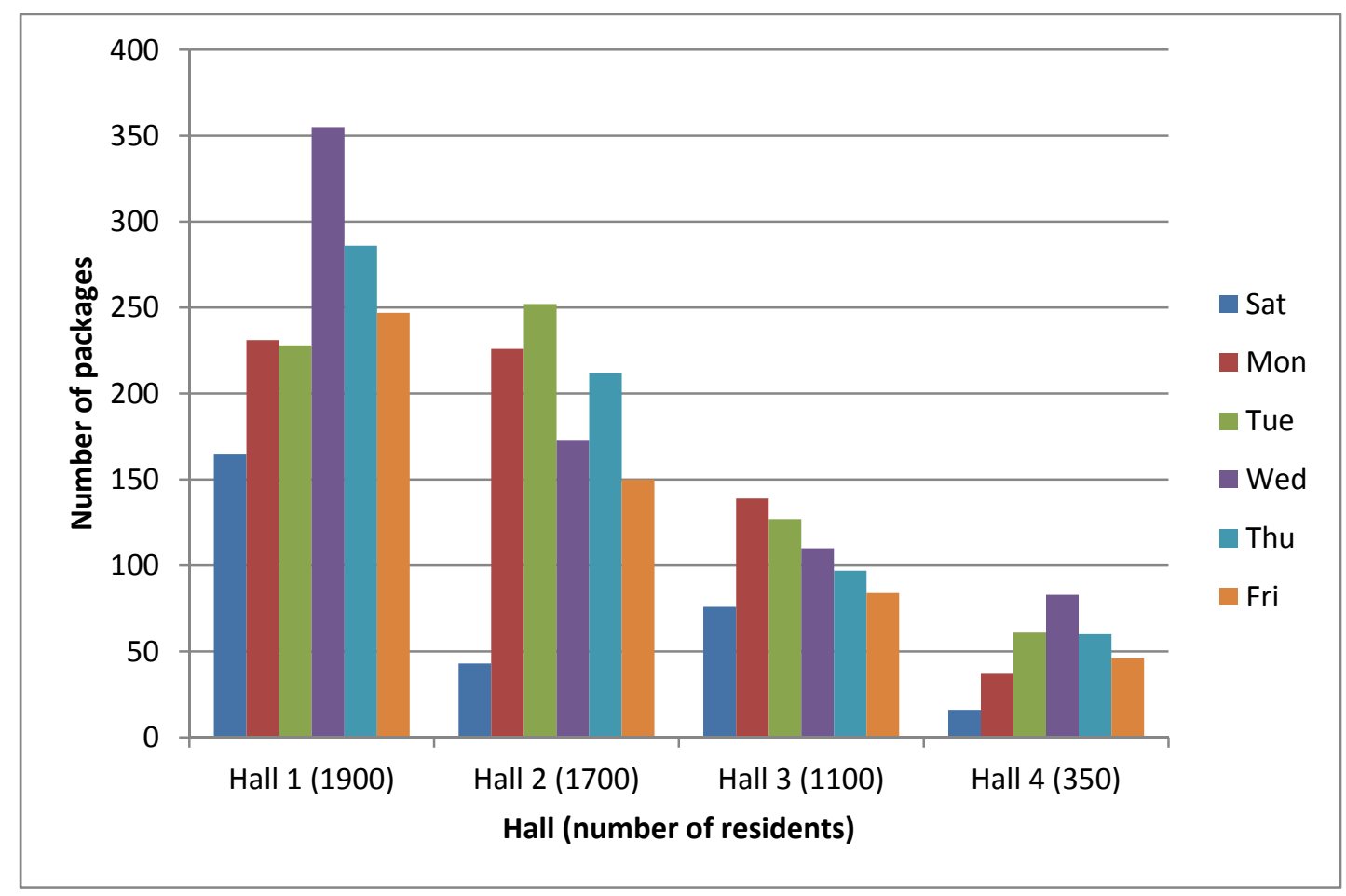

Figure 5. Numbers of parcels delivered to University of Southampton halls of residence during the survey period (Saturday 28/11/15 - Friday 4/12/15, 09:00 to 17:00).

A breakdown by courier showed that Royal Mail delivered the greatest number of parcels (834, the vast majority of which (659) were to the largest hall), followed by Hermes (556), Amazon (507), DPD (186), Parcelforce (166) and Yodel (118). Dividing the number of packages delivered by the number of visits, for each carrier and for each hall gave some indication of the level of efficiency of each operation. Most efficient, on this basis, was Royal Mail at Hall 1, who delivered an average 94 parcels per visit, with their average across the 
four halls being 35 parcels per visit. They were followed by Hermes ( 25 parcels per visit), TNT (24) and Amazon (23); all other carriers averaged fewer than 10 parcels per visit.

\subsubsection{Volumes of packages delivered}

The total volume of packages delivered during the survey week was estimated for both the University of Southampton, using the categorisation method described in section 4.3, and for Southampton Solent University, where similar categorised data were available from their goods receipting system (Table 2). This indicated that the University of Southampton generated five times more deliveries, by volume, than Southampton Solent University. Comparison with the annual data (section 4.3.2) indicated that the volumes for the Black Friday week were around 2.2 times greater than the average weekly volume at Southampton Solent University.

Table 2. Volume of packages delivered $\left(\mathrm{m}^{3}\right)$ to Southampton University (SU) and Southampton Solent University (SS) halls of residence (Saturday 28/11/15 - Friday 4/12/15, 09:00 to 17:00).

\begin{tabular}{llllllll}
\hline $\begin{array}{l}\text { Hall } \\
\text { (\#residents) }\end{array}$ & Sat & Mon & Tue & Wed & Thu & Fri & Total \\
\hline Hall 1 $(1,900)$ & 6.8 & 10.8 & 12.5 & 11.8 & 11.6 & 7.6 & 61.2 \\
Hall 2 $(1,700)$ & 1.7 & 10.3 & 9.4 & 5.4 & 8.3 & 6.5 & 41.6 \\
Hall 3 $(1,100)$ & 3 & 7.8 & 4.3 & 2.7 & 2.4 & 2.7 & 22.9 \\
Hall 4 (350) & 0.7 & 1.1 & 2.1 & 4.4 & 1.8 & 1.6 & 11.7 \\
\hline SU Total & $\mathbf{1 2 . 2}$ & $\mathbf{3 0}$ & $\mathbf{2 8 . 3}$ & $\mathbf{2 4 . 3}$ & $\mathbf{2 4 . 1}$ & $\mathbf{1 8 . 4}$ & $\mathbf{1 3 7 . 3}$ \\
\hline Hall 1 (208) & 0.53 & 0.68 & 0.42 & 0.74 & 0.68 & 0.79 & 3.8 \\
Hall 2 (422) & 1.2 & 1.28 & 2.0 & 2.2 & 1.3 & 1.3 & 9.3 \\
Hall 3 (240) & 0.55 & 0.74 & 0.44 & 0.92 & 1.1 & 0.55 & 4.3 \\
Hall 4 (228) & 0.28 & 0.36 & 0.64 & 0.88 & 0.84 & 0.52 & 3.5 \\
Hall 5 (391) & 1.1 & 1.4 & 1.3 & 1.0 & 0.48 & 1.3 & 6.6 \\
\hline SS Total & $\mathbf{3 . 6 4}$ & $\mathbf{4 . 4 2}$ & $\mathbf{4 . 7 9}$ & $\mathbf{5 . 7 3}$ & $\mathbf{4 . 4 5}$ & $\mathbf{4 . 4 9}$ & $\mathbf{2 7 . 5}$ \\
\hline
\end{tabular}

\subsubsection{Seasonal trends in package delivery}

The Southampton University halls post audit covered a week's worth of delivery activity following the Black Friday e-retail event. To look at the wider delivery trends across the academic year, data from the package receipt system at Southampton Solent University covering 5 of their halls between $1^{\text {st }}$ September and the $30^{\text {th }}$ June 2016 were used (Figure 6 ). The data confirmed the observation made by a hall manager that parcel volumes are greatest just after students receive their grant cheques (October, January and just after Easter) with October and January being the busiest months for package receipt, with just over 2,500 parcels per month. Weekly analysis confirmed that the week immediately following the Black Friday sales event received the most deliveries (761 parcels across the five halls, 1,489 residents) with the next busiest being the week commencing $18^{\text {th }}$ January, likely related to January sales and incoming grant cheques. The observed quiet periods corresponded to Christmas, Easter and summer vacations when few students remain in halls. 


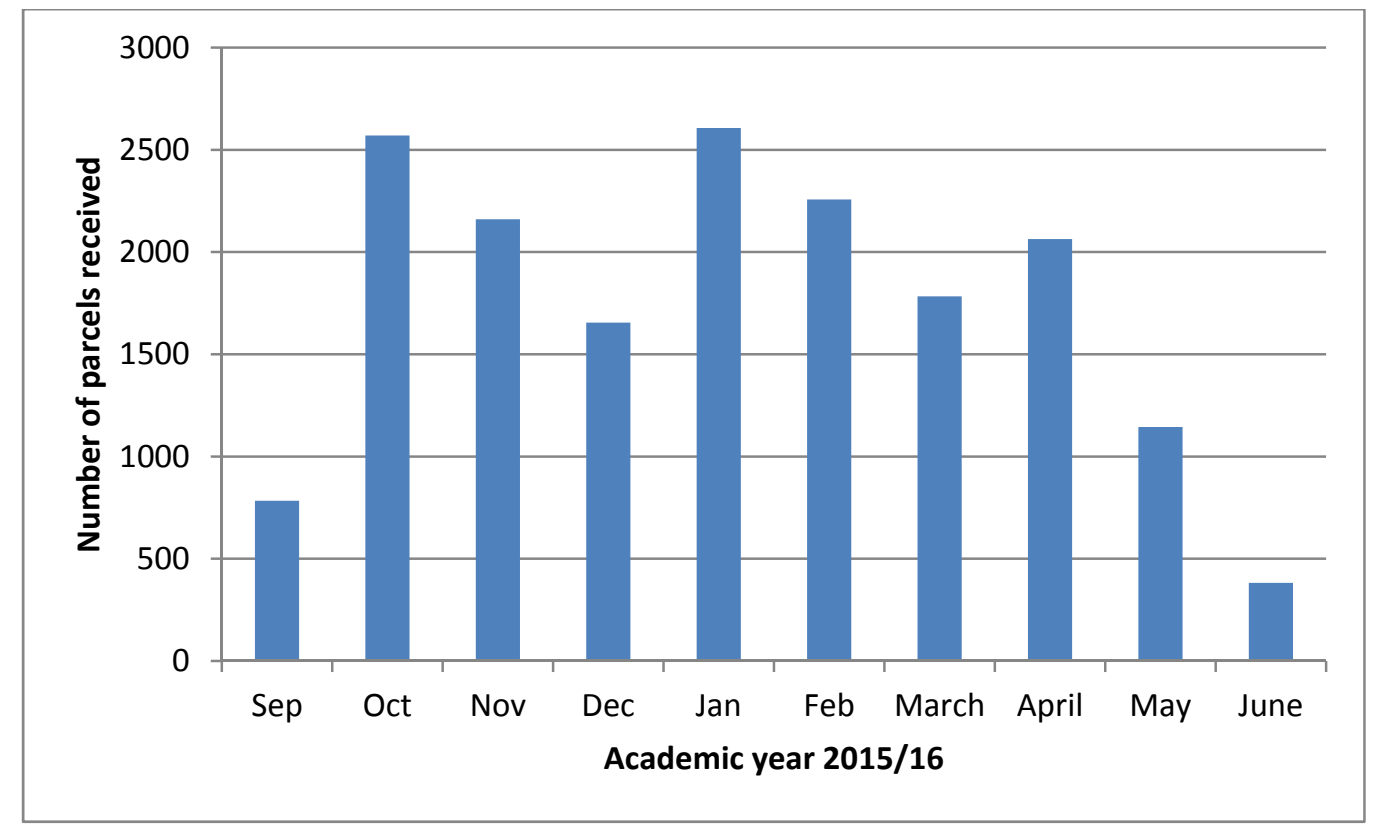

Figure 6. Seasonal trend of parcel volumes received across 5 halls of residence $(1,489$ residents) at Southampton Solent University (September 2015 to June 2016).

\subsection{Package volumes and inferences for UCC adoption}

The data collected from the halls delivery audits were extrapolated to consider the annual delivery requirements for all the student halls, including those not surveyed (Table 3 ). This suggested that the two universities might expect to receive across their 14 student hall complexes (8,886 residents), around 128,000 packages per year, (a mean of 14 packages per student per year). These would be delivered by around 20 different logistics providers across 13,500 visits. The total estimated volume $\left(4,194 \mathrm{~m}^{3}\right)$ equates to 4,194 roll cages (a typical roll cage has $1 \mathrm{~m}^{3}$ capacity), or a daily equivalent of 17.5 roll cages, if one assumes a 40-week academic year (mid-September to mid-June) and deliveries six days a week. Depending on the delivery time requirements of the university halls, such volumes could be consolidated onto either a single 18-tonne rigid lorry or onto two smaller vehicles each day rather than the estimated 56 separate vehicles currently experienced.

Table 3. Estimated annual delivery activity to 14 halls of residence serving Southampton and Southampton Solent universities.

\begin{tabular}{lrrr}
\hline & $\begin{array}{r}\text { University of } \\
\text { Southampton }\end{array}$ & $\begin{array}{r}\text { Southampton } \\
\text { Solent } \\
\text { University }\end{array}$ & Total \\
\hline No. of halls & 8 & 6 & 14 \\
No. of residents & 6,592 & 2,294 & 8,886 \\
No. of packages & 101,601 & 26,822 & 128,423 \\
No. of courier visits & 8,249 & 5,263 & 13,512 \\
Package volume $\left(\mathrm{m}^{3}\right)$ & 3,392 & 802 & 4,194 \\
\hline
\end{tabular}




\subsubsection{How a consolidated halls post system might function}

Working with the operator of an existing UCC in Southampton (Meachers Global Logistics $\left.(\mathrm{MGL})^{1}\right)$, a theoretical consolidated halls post system serving the 14 halls of residence across the two universities was devised and would offer the following service:

Redirection of deliveries - Deliveries to student halls would be made via the Southampton Sustainable Distribution Centre (SSDC), located on the Nursling Industrial Estate on the western side of Southampton (Figure 7). Students would be instructed to give their delivery address as 'Hall name, c/o SSDC address' and this would be reinforced by informing the major carriers, including Royal Mail, to redirect all participating hall deliveries via the SSDC.

Receipting - MGL would take receipt of hall deliveries using the same receipting systems as those currently used by the two universities so that staff and students would retain the same visibility and tracking currently experienced.

Sorting - Parcels would be sorted at the SSDC into roll cages or other suitable containment devices for subsequent delivery. The sorting would be arranged to suit the halls with alternative options envisaged (e.g. by student surname and/or by hall block, where requested).

Delivery round - Each hall would receive a single delivery each day from MGL at a time to suit the halls staff and students. A single delivery vehicle would be used where possible, operating on a milk round basis, visiting halls in turn. While it may be possible to cater for specific delivery demands from one or more halls, it would likely not be practical or efficient, if all halls demanded a strict delivery time window, especially if they were similar. The shortest vehicle route around the 14 halls, starting and ending at the SSDC, was estimated to be $32 \mathrm{~km}$, with a free-flow travel time, excluding stops or possible traffic delays, of 1 hour 11 minutes, using commercially available vehicle routing software (DPS Route Optimiser ${ }^{2}$ ) (Figure 7). Environmental benefits would be enhanced by the use of an electric vehicle for deliveries, a practical proposition here as the delivery round would be relatively short.

Delivery - Delivered items would be transferred from the roll cages or other containers into the hall's own permanent storage racks/areas. This could either be done by MGL on delivery, or by hall reception staff subsequently, with empty roll cages/containers being picked up by MGL on a subsequent delivery visit. The former option would likely be preferred by halls where there is little or no storage space available. It should be noted that roll cages could not act as a replacement for hall storage racks as they would not be emptied from one day to the next, with observations suggesting that some students could take several days to collect their items.

\footnotetext{
${ }^{1}$ https://www.meachersglobal.com/

${ }^{2}$ http://www.dps-int.com
} 


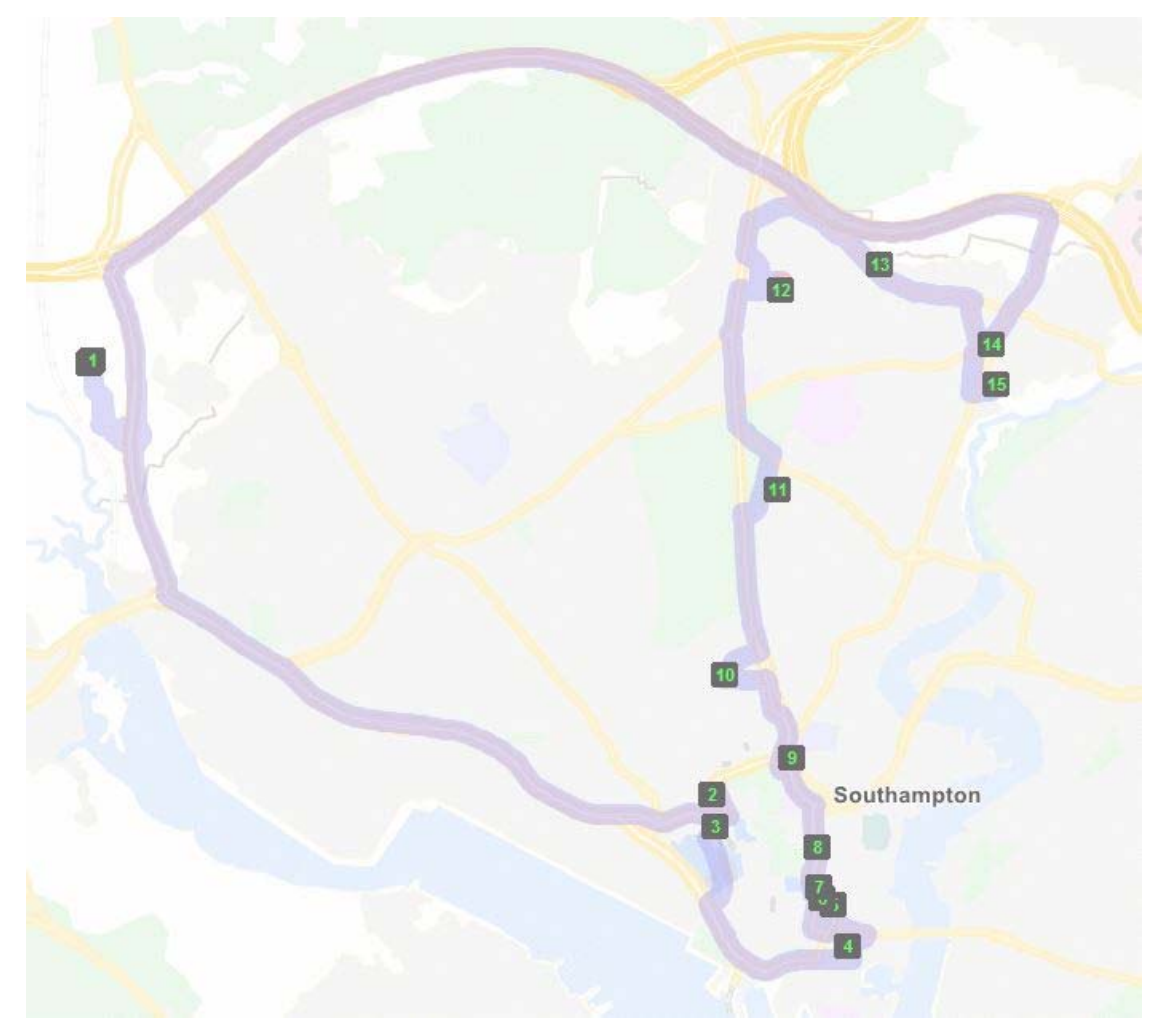

Figure 7. Shortest path route $(32 \mathrm{~km})$ for servicing university halls across Southampton $(2$ to 15) from the current Sustainable Distribution Centre (1) operated by Meachers Global Logistics.

\subsubsection{Handling special and time dependent deliveries}

Of concern with moving to a consolidated halls post concept is how special and timed deliveries should be handled, given that the consignee may have paid a premium to receive the item before a certain time. From a legal perspective, it may be difficult for an HEI to restrict such requests and limit residents to the timings of a managed halls post service. The results from the package receipt audits and student preference data suggested that sameday and next-day before $12 \mathrm{pm}$ deliveries could account for $7 \%$ and $5 \%$ of the deliveries received respectively, and that as a result, approximately $40 \%$ of courier visits may continue to be made if these urgent deliveries were excluded from the consolidation scheme. On this basis, consolidation could have the potential to reduce the total number of delivery visits to halls by $35 \%$, from the current 13,512 (Table 3 ) to 8,765 , that is 5,405 direct by couriers with 3,360 consolidated deliveries via the consolidation centre (14 halls $\times 40$ weeks $\times 6$ days/week). In this case, where urgent and timed deliveries were excluded, a single van (e.g. a long wheel based Transit) may be sufficient for use.

\subsubsection{Estimating the costs of a consolidated halls post service}

The cost of providing the consolidated delivery service would be associated with the following: receiving and receipting in packages from couriers; grouping packages together and loading onto vehicles; warehouse storage space; making the deliveries; and associated staff and vehicle operating costs. To derive an estimate of service cost, the estimated annual package throughputs (Table 3 ) across all 14 halls covering both universities (8,886 residents) were used, under a theoretical policy that all purchases made by students for home delivery would have to go via the SSDC.

Based on the combined annual delivery volume of $4,194 \mathrm{~m}^{3}$ estimated for both universities' halls and assuming the use of a long wheelbase van with a carrying capacity of $14 \mathrm{~m}^{3}$, MGL estimated that their service would equate to an approximate average cost of $£ 17.88$ per 
student per year (Table 4), based on a 40-week academic year (mid-September to mid-June) and 6 day week service (not including Sundays).

Table 4. Estimated consolidated delivery cost based on a combined annual delivery volume of $4,194 \mathrm{~m}^{3}$ packages to both universities in Southampton using a long wheelbase van (capacity $14 \mathrm{~m}^{3}$ )

\begin{tabular}{lllrr}
\hline Item & Requirement & Daily rate & £ per day & $\begin{array}{r}\boldsymbol{E} \text { per year } \\
\text { (40 wks x 6 days/wk) }\end{array}$ \\
\hline Driver and vehicle & 10 hrs/day & $£ 35 / \mathrm{hr}$ & 350 & 84,000 \\
Warehouse admin & 14 hrs/day & $£ 18 / \mathrm{hr}$ & 252 & 60,480 \\
Warehouse space & $1,000 \mathrm{sq} . \mathrm{ft}$ & $£ 0.06 / \mathrm{sq} . \mathrm{ft} /$ day & 60 & 14,400 \\
\hline Total & & 662 & 158,880 \\
Cost per student $(=$ Total/8,886) & & 0.07 & 17.88 \\
\hline
\end{tabular}

\subsubsection{The implications for halls staff from adopting a consolidated post system}

One major advantage of adopting a consolidated halls post service would be the potential time saved by reception staff from receiving a single receipted and pre-sorted delivery rather than having to deal with multiple couriers arriving throughout the day. A senior halls manager undertook a time-and-motion assessment to quantify the amount of time spent by reception staff on specific tasks related to managing student post. The results (Table 5) suggested that the present system could take 210 minutes of receptionist's time per day of which 60 minutes would be spent dealing with couriers, 100 minutes logging parcels into the system and 30 minutes liaising with students to handover items (Table 5). It was estimated that up to 20 minutes per day could be spent retrieving packages delivered to other halls in cases where a reception desk had been unattended when the courier arrived. With the receipting and booking in processes outsourced to the UCC, it was estimated that a halls receptionist could save in the order of two hours per day which could be reallocated to other tasks.

Table 5. Estimated time savings for an individual member of reception team per day

\begin{tabular}{lrr}
\hline Task & \multicolumn{2}{c}{ Time spent (minutes) } \\
& Now & After consolidation \\
\hline Receiving goods from courier & 60 & 30 \\
Logging parcels onto computer system & 100 & 20 \\
Retrieving parcels delivered to another hall & 20 & 10 \\
Handing parcels over to students & 30 & 30 \\
\hline Total & 210 (3.5 hours) & 90 (1.5 hours) \\
\hline
\end{tabular}

\section{Results - Student online shopping survey}

Having established the extent of package delivery to halls of residence as a result of students' online purchasing, the next step was to investigate the reasons behind these observations and how students might react to the imposition of a consolidated delivery service.

\subsection{Products ordered for home delivery and delivery options chosen}

Students ordered a diverse range of products for home delivery. Clothing and footwear topped the items purchased online ( $41 \%$ ordered at least once per month) which reflects national market intelligence data (Mintel 2015c) and European retail experiences where 48\% of customers purchase in this category (Eurobarometer, 2013). Takeaway meals were also a significant product purchased for delivery to halls (38\% ordered at least once per month) and generate substantial small vehicle trips with $40 \%$ of meal deliveries in the UK being ordered 
online (Daily Telegraph, 2016) and Deliveroo having over 3,000 registered couriers in London alone (The Guardian, 2016).

Students typically selected standard delivery for non-food items with $58 \%$ stating that $90 \%$ of their online purchases came via that option. Other options were used, with $14 \%$ of the respondents purporting to be regular users of next-day delivery services with $90 \%$ of their online purchases coming via that route reflecting the growth in this area (Ofcom, 2015). Same-day delivery was rarely used with $86 \%$ of respondents stating that they had never used it. This is usually the most expensive delivery option and reflects Ofcom's (2015) finding that $60 \%$ of customers do not want to pay for upgraded services which will be enhanced by the generally restricted budgets of students. Delivery to collection points, such as unattended lockers ( $90 \%$ never used) or convenience stores ( $86 \%$ never used), were also unpopular choices with click-and-collect in-store proving a more commonly chosen alternative with only $56 \%$ of respondents stating that they had never used it.

Attitudes to delivery indicated preferences for cheaper options reflecting student budgets, however, next day delivery would be used where items were needed urgently $(81 \%$ agree). During the Black Friday sale week, $42 \%$ of the respondents made a purchase with clothing and footwear being the most prominent items purchased $(28 \%)$. Of students making purchases during this week, the majority made 1 or 2 purchases $(66 \%)$, however $16 \%$ purchased 4 or more items indicating a group of more frequent online shoppers.

Product purchase habits and delivery options were examined in relation to gender and fee status (home/EU versus international students). The analysis indicated some demographic patterns but effect sizes were small and suggested these factors play a limited role. No evidence was found to suggest that HEls with all-female halls of residence would see significantly different purchasing habits compared to all-male halls.

\subsection{Investigating the characteristics of frequent shoppers}

In order to identify frequent purchasers, the purchase responses were given numeric codes $(1=$ 'never purchase this item online' to $8=$ 'purchase this item more than once per week'). This provided a scale that was then summed across the 15 items for each respondent to give a measure of purchase frequency with scores theoretically ranging from 15 (people who never purchase on line (3.2\% of sample)) to 120 (people who purchase all items more than once per week ( $0 \%$ of sample)). The respondents were then split into two groups around the mid-point in the data (score of 30 or less $=$ infrequent shopper $(47.4 \%)$, score of $>30=$ frequent shopper $(52.6 \%)$.

Mann-Whitney $U$ tests revealed frequent shoppers were statistically more likely to use a range of more time-dependent delivery options and collection points (Table 6) and are therefore likely to be driving the growth in non-standard delivery formats (Ofcom, 2015). This group were more concerned about speed of delivery as they were likely to choose next-day services, more willing to pay for same-day delivery and consider this will be an important consideration for them in the future. Frequent shoppers therefore seek to reduce the delay in product gratification (Park and Kim, 2007) and are therefore less likely to accept the consolidation option, however, though significant effects were found, the effect sizes were small and this pattern is not marked. Frequent shoppers were also more likely to consider locker banks important and less likely to choose the cheapest delivery option. During the Black Friday sales week, frequent shoppers were associated with significantly more online purchases $\left(X^{2}{ }_{(1)}=16.90, p<.001\right)$ and based on the odds ratio, the odds of purchase during Black Friday week were 2.4 times higher for frequent online shoppers. 
Table 6. Frequent shopper effects on delivery options. Mann-Whitney test results

\begin{tabular}{|c|c|c|c|c|}
\hline \multirow[b]{2}{*}{ Home delivery options } & \multicolumn{2}{|c|}{ 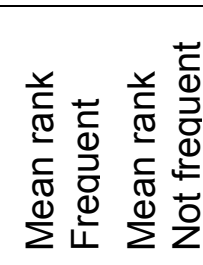 } & U & \multirow[t]{2}{*}{$r$} \\
\hline & & & & \\
\hline $\begin{array}{l}\text { Standard delivery during the working day (Packages arrive in } \\
\text { the daytime within } 5-63 \text { days) }\end{array}$ & & & NS & \\
\hline Next Day delivery (No time mentioned) & 228 & 172 & 25,632 & $.25^{* *}$ \\
\hline Next Day AM delivery (7:00 - 12:00) & 212 & 184 & 22,332 & $.18^{* *}$ \\
\hline Next Day PM delivery (12:00 - 18:00) & 214 & 183 & 22,730 & $.20^{* *}$ \\
\hline Next Day evening delivery $(17: 00-22: 00)$ & 215 & 181 & 23.079 & $.23^{* *}$ \\
\hline Same-day delivery & 210 & 187 & 21.870 & $.16^{* *}$ \\
\hline Weekend delivery & 212 & 185 & 22,339 & $.18^{* *}$ \\
\hline Delivery to a Collect Point lockerbank & 205 & 192 & 20,963 & $.11^{*}$ \\
\hline Delivery to a Collect Point convenience store & & & NS & \\
\hline Click and collect in-store & & & NS & \\
\hline \multicolumn{5}{|l|}{ Attitudes towards home delivery options } \\
\hline Wherever possible I choose next day delivery & 224 & 180 & 28,879 & $.19^{* *}$ \\
\hline $\begin{array}{l}\text { I would be prepared to wait longer for my goods if it meant the } \\
\text { retailer could bundle them together into one delivery }\end{array}$ & & & NS & \\
\hline I would be prepared to pay extra to have same-day delivery & 219 & 185 & 23,816 & $.15^{\star *}$ \\
\hline $\begin{array}{l}\text { Same-day delivery services will be important to me in the } \\
\text { future }\end{array}$ & 218 & 185 & 23,643 & $.14^{* *}$ \\
\hline Providing Locker banks around campus would be useful to me & & & NS & \\
\hline I would choose whichever is the cheapest delivery option & & & NS & \\
\hline I only choose next-day delivery when I need an item urgently & & & NS & \\
\hline
\end{tabular}

$U$ is Mann-Whitney's $U$ statistic, $r$ is the effect size estimate

*Significant at $p<.05$

** Significant at $p<.01$

NS is not significant

\subsection{Attitudes towards a consolidated delivery service via a UCC}

The consolidated delivery concept was positively received by students as $84 \%$ were generally 'not too bothered how parcels arrive'. The students also stated that they had reasonable levels of trust that the university had the competence to deliver the service $(72 \%$ agreed) but $81 \%$ expressed concern about who would be responsible for loss or damage to packages, making performance risk (Shin et al., 2016) a potential barrier.

Students were understandably cost sensitive $(79 \%$ preferred a standard delivery with the lowest cost) reflecting general customer views that free delivery is important (Ofcom, 2015). Related to this, speed was less of a barrier (32\% agreed same-day deliver is important) 
which is encouraging for the consolidated delivery model. Consolidated delivery would provide students with a time window in which they would expect to receive deliveries and given that customers like tracking and delivery notification (Ofcom, 2015), would be an added benefit. Open ended comments indicated students often experienced some delay in parcel receipt even when the parcel had arrived at the hall due to notification and handling problems which consolidation would help mitigate.

There were some small effects related to gender and fee status, however, no strong evidence of marked differences based on demographic characteristics. The frequent purchase group were more likely to get 'swept up in the excitement of the moment' (Zimbado, 1999) (frequent purchase mean rank $=219$, non-frequent purchase mean rank $=184, U=$ $23,958, p<.01, r=.16$ ) and more likely to choose the fastest delivery option regardless of cost (frequent purchase mean rank $=221$, non-frequent purchase mean rank $=181, \mathrm{U}=$ $24,197, p<.001, r=.18)$. These are both time critical issues, the latter being a barrier to the proposed solution since some of the faster delivery options will be compromised by routing through the UCC, however, effect sizes were small.

The attitudes of respondents towards consolidated delivery were explored further using cluster analysis to identify groups. Ward's method was used, which minimises within-group variation (Hair et al., 2010), and a squared Euclidean distance measure. Two outliers were removed during analysis and a three-cluster solution emerged that was conceptually most useful.

Cluster $1(n=183)$ - 'Contented and speed ambivalent' - this cluster is happy with the status quo and trust their university to handle goods. Speed of delivery is not an issue.

Cluster 2 ( $n=64)$ - 'Speed concerned sceptics' - lack trust in their university's ability to handle goods and are unhappy about current deliveries procedures. Speed is an issue. Same day delivery is reasonably important.

Cluster $3(n=150)$ - 'Contented but speed, risk and cost concerned' - trust their university to handle goods, but concerned about responsibility for damage/loss, get swept up in the moment, and more likely to choose fast delivery options.

Clusters 2 and 3 were associated with frequent shoppers $\left(X^{2}{ }_{(2)}=11.452, p<.003\right)$. While cluster 1 indicated acceptance of the scenario, this group shopped online less and it is therefore the attitudes of clusters 2 and 3 which will most influence success of a consolidated delivery initiative. Cluster 2 demonstrated least acceptance of the scenario which reflects a degree of unhappiness with existing procedures and concerns about delivery speed. Cluster 3 , on the other hand, indicated acceptance of the scenario with some reservations. Therefore while overall, the picture is quite positive for acceptance, there is evidence of a resistant group and potential barriers that would need to be overcome (Figure 8). 


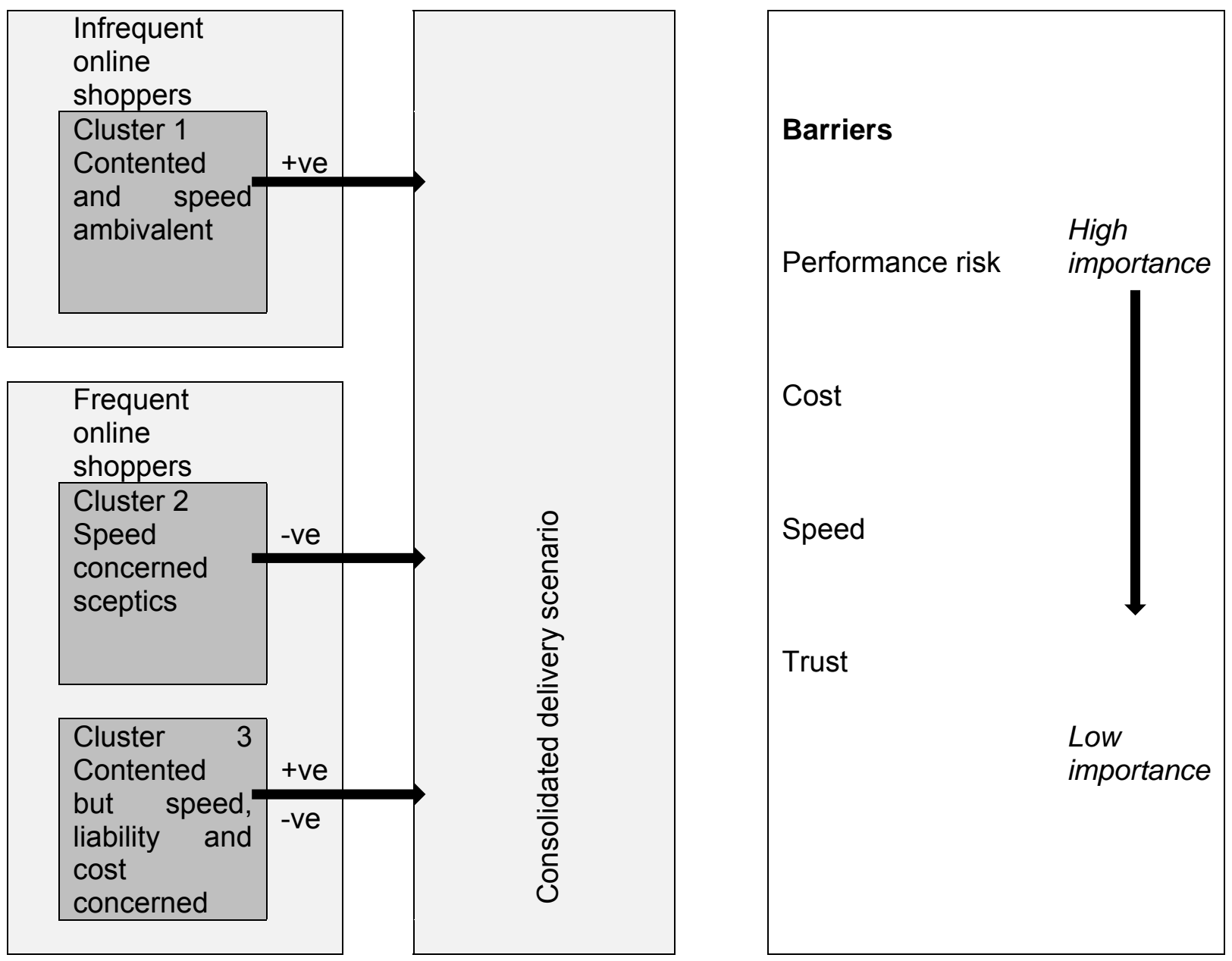

Figure 8. Attitudinal barriers to a proposed consolidated delivery scenario

\subsection{Preferred collection times and inferences for consolidated deliveries}

Any consolidated delivery service would need to establish the most convenient delivery time with each hall as part of a milk round type service. The survey suggested the most favoured time was between 17:00 and 19:00, with the next either side of this (Table 7) and it was concluded that a service supplying halls with parcels in the late afternoon would be acceptable to residents.

Table 7. Preferred parcel collection times of students in University of Southampton halls of residence $(n=405)$

\begin{tabular}{ll} 
Time of day & Average rank $\left(\mathbf{1}^{\text {st }}\right.$ to $\left.\mathbf{6}^{\text {th }}\right)$ \\
\hline $07: 00-09: 00$ & 4.99 \\
$09: 00-12: 00$ & 4.27 \\
$12: 00-14: 00$ & 3.76 \\
$14: 00-17: 00$ & 2.88 \\
$17: 00-19: 00$ & 2.11 \\
$19: 00-23: 00$ & 2.93 \\
\hline
\end{tabular}




\section{Discussion and conclusion}

Urban Consolidation Centres (UCCs) with the capacity to consolidate parcel deliveries for urban locations present a good opportunity to address externalities arising from online retail. The potential of this opportunity depends on the key stakeholders who supply and deliver products and the end customers. This paper has presented an analysis of a theoretical consolidated parcel delivery service for student halls of residence using historic parcel receipt records for 14 halls in Southampton, UK. It has analysed the scale of the parcel delivery problem, the student purchasing traits generating the activity and identified the extent to which this could be addressed by a parcel consolidation solution. It has also addressed the under researched area of customer views on delivery choices and provides an initial evidence base.

With over 385,000 students living in halls of residence at UK HEls and with many UK cities having purpose-built complexes housing over 8,000 residents, this research suggests that in such instances, over 13,000 courier trips could be generated annually as a result of students' online purchasing behaviours. With the drive to make HEls more efficient and reduce their environmental impact, addressing the secondary effects of their students' activities might be one way to help achieve this. There is therefore a strong organisational imperative to act. Reducing the transport footprint to halls of residence could not only benefit an HEI but also the local authority and residents who would potentially gain from reduced vehicle activity, reduced parking infringements, improved air quality and journey times across the surrounding urban area. The analysis of courier activity to 14 halls in Southampton suggested that courier vehicle visits could be reduced from 56 per day to 1 using consolidated deliveries. Additional benefits gained by HEI halls' staff due to a much reduced level of interruption to daily operations would add to the cost-benefits of implementing the service.

Consolidated parcel delivery is likely to be accepted by students; however, there are caveats. This study reinforces the evidence that young people are active in online retail with clothing/footwear and takeaway food leading the items purchased. While the latter presents no opportunity for consolidation, clothing represents a relatively low-cost, non-urgent product which is suited to consolidated delivery.

The student customers were most concerned about potential loss of or damage to goods but this was considered to have been over-emphasised as an artefact of survey design since few people would be unconcerned about loss or damage to items. Analysis indicated numerous relatively low-value purchases were delivered during Black Friday week. As delivery performance risk increases with item value, this concern is likely to be marginal for most items, especially clothing and footwear which are commonly purchased. The number of online purchases made by students supports Chapparo-Peláez et al. (2016) who found delivery performance risk was not a significant barrier in online retail. However, the addition of a UCC adds to the supply chain and potential opportunities for loss or damage to items. A consolidation solution will therefore need to address which organisation covers the liability for missing or damaged goods.

Additional costs derived from consolidation would also be a concern for student customers reflecting the general population's desire for 'free delivery'. In this research, a consolidated halls post service via a UCC serving 14 halls of residence (8,886 residents) generating an estimated $4,194 \mathrm{~m}^{3}$ of packages per annum over a 40 -week academic year was estimated to cost $£ 17.88$ per student per year. Consideration therefore needs to be given to funding the initiative, raising questions concerning how to allocate costs relative to the benefits of a UCC scheme. Much therefore depends on how the cost-benefits are perceived by universities and local authorities involved. Costs could be recovered from students through halls fees and hidden from these end users, though there are arguable ethical issues here, since students will make differential use of the service. Some costs might also be apportioned to carriers 
who benefit from time savings through avoiding deliveries to congested urban areas; however, this benefit may not exist where carriers continue to make other deliveries in these areas.

Speed of delivery is important to online purchase decisions but this research and the wider body of knowledge suggests that shoppers, and particularly cost-conscious students, are not prepared to pay for upgraded and faster delivery services. This is advantageous from the perspective of a consolidated halls post service via a UCC which would struggle to meet same-day or early morning next-day deliveries due to the time required for the consolidation element which necessarily introduces some delay. For non-urgent items, likely to be the majority of cases, the delay is unlikely to be important given the student attitudes revealed in the online survey and in the observation that some items can sit in hall receptions for several days before being collected. However, some students will want text books or other items urgently for legitimate reasons, and it is questionable whether the student should, or could, be denied access to premium delivery services.

At the same time, increasing numbers of carriers are moving towards next-day delivery, as standard, at no extra cost, further shifting customer delivery expectation norms. The UCC operator would have to implement a cut-off time for receiving goods in order to guarantee delivery on the same day as they were received from the couriers. For more frequent online shoppers, this might pose a problem if a retailer was offering a guaranteed next-day delivery for orders placed by 22:00 and the UCCs cut-off time for consolidation was 21:00. In this circumstance, the student would not receive their package until two days after the order was placed which contravenes the 'next-day' guarantee given by the retailer.

Analysis indicates frequent shoppers seek to reduce the delay in product gratification (Park and Kim, 2007) and a proportion could reject the consolidation option if it did not meet their delivery requirements for specific products, however, the effect sizes in this study were found to be small. This issue would be highlighted further where retailers offering online order tracking inform the consignee that the delivery has been made when it is in fact only at the UCC and not, as the student may believe, at their hall reception. To counter this, it might be possible to exclude premium delivery items from the consolidation service but this could undo many of the transport-related benefits if significant numbers of couriers $(40 \%$ in this research), continue to visit the halls. Related to the temporal dimension of speed is the transparency of deliveries. A consolidated delivery late-afternoon would be most acceptable to students and has the advantage that students would know when to expect parcels to arrive, an improvement on the existing service. There are also time-saving benefits for couriers from having a single drop location (the UCC) instead of deliveries to several different halls across an urban area.

Potential challenges to be considered include enforcement of the new delivery address making good communication with students and couriers essential. Such a scheme would ideally commence at the start of a university year, with all incoming hall residents being informed of the new delivery address, the rationale and their contractual responsibilities as halls residents. It would also be essential to instruct the main couriers about the required redirections to avoid them delivering direct to halls rather than via the UCC. Previous research indicates that UCCs are successful only if the imposing organisation is able to control or strongly influence all the potential carriers and receivers of goods (Allen et al., 2012). This has previously been achieved in the case of construction project UCCs and UCCs that serve large sites with a single landlord. In this instance, although universities have an opportunity to communicate with students, the reality is they have little control over which address students use. The carriers involved will also be serving other addresses in the area and may have little incentive to divert parcels to the UCC. Space at halls is also a challenge and is likely to impact on the transfer strategy. There are also operational issues to address such as the courier requirement for the recipient's signature and undeliverable items, for example, where the student no longer resides at the hall. 
The analysis presented in this paper is based on an understanding of existing parcel delivery practices and views of a proposed consolidated parcel delivery solution. Further research is therefore needed to test the initiative through a pilot of parcel consolidation to student halls. While the analysis in this paper is contextual to a specific accommodation and organisational context, the findings offer insight to other urban contexts. There are direct parallels with other forms of large serviced accommodation blocks with implications for the design of new buildings to facilitate delivery and storage. Indirectly, knowledge can also be transferred to non-serviced accommodation blocks and densely populated urban areas in the effort to address environmental externalities. For example, a consolidated delivery service would provide end customers with better knowledge of when parcels might arrive if a regular known route was used. This would reduce the incidence of parcel delivery failure in comparison to the current dominance of relatively open-ended delivery times. Given the university specific context of this study, further work is needed in other domains to explore customer views of consolidation, scope for consolidation implementation and its potential to address existing delivery problems and environmental externalities.

The home delivery sector has evolved in a neoliberal political climate with little external regulation and the highly competitive industry that has resulted embeds much inefficiency. While there are economic imperatives to address this at a company level, there is little incentive to rationalise deliveries with other couriers. The growing recognition of environmental externalities associated with home delivery will increasingly pose problems for retailers as well as couriers. Further research therefore needs to better understand the industry perspective, the scope for new practices and their capacity and willingness to take action.

\section{Acknowledgements}

The authors would like to acknowledge the support provided by hall managers and reception staff at both the University of Southampton and Southampton Solent University. The project (www.citylab-project.eu) has received funding from the European Union's Horizon 2020 research and innovation programme under grant agreement no. 635898.

\section{References}

Allen, J., Browne, M., Woodburn, A., Leonardi, J., 2012. The role of urban consolidation centres in sustainable freight transport. Transport Reviews, 32(4), 473-490.

Association of University Directors of Estates, 2014. Higher Education estates statistics report 2014. http://www.aude.ac.uk/documents/aude-he-estates-statistics-report-2014/. Accessed 10 January 2017.

Boudouin, D., 2006. Les espaces logistiques urbains : Guide methodologique. Paris : La Documentation Francaise (in Allen et al., 2012).

Browne, M., Allen, J., Sweet, M., Woodburn, A., 2005. Urban Freight Consolidation Centres ; Final Report. London: Transport Studies Group, University of Westminster.

http://ukerc.rl.ac.uk/pdf/RR3 Urban Freight Consolidation Centre Report.pdf Accessed 26 August 2016.

Browne, M., Rizet, C., Allen, J., 2014. A comparative assessment of the light goods vehicle fleet and the scope to reduce its $\mathrm{CO}_{2}$ Emissions in the UK and France. Procedia - Social and Behavioral Sciences 125, 334-344. 
Chaparro-Peláez, J., Agudo-Peregrina, A.F., Pascual-Miguel, F.J., 2016. Conjoint analysis of drivers and inhibitors of e-commerce adoption. Journal of Business Research, 69, 12771282

Cherrett, T., Allen, J., McLeod, F. Maynard, S., Hickford, A., Browne, M., 2012.

Understanding urban freight activity - Key issues for freight planning, Journal of Transport Geography, 24, 22-32.

Daily Telegraph, 2016. Deliveroo revenue to hit $£ 130 \mathrm{~m}$ this year.

http://www.telegraph.co.uk/technology/2016/06/05/deliveroo-revenue-to-hit-130m-this-year/. Accessed 10 January 2017.

Department for Transport, 2015. Road Traffic Statistics.

https://www.gov.uk/government/statistical-data-sets/tra01-traffic-by-road-class-and-regionmiles Accessed 12 September 2016.

Edwards, J., McKinnon, A., Cullinane, S., 2010. Comparative analysis of the carbon footprints of conventional and online retailing: A "last mile" perspective. International Journal of Physical Distribution \& Logistics Management 2010 40(1/2), 103-123.

Eurobarometer, 2013. Consumer attitude towards cross-border trade and consumer protection Flash Eurobarometer 358. http://ec.europa.eu/public opinion/flash/fl 358 en.pdf Accessed 13 September 2016.

Flavián, C., Guinalíu, M., Gurrea, R., 2006. The role played by perceived usability, satisfaction and consumer trust on website loyalty. Information \& Management, 43, 1-14.

Gonzalez-Feliu, J., Morana, J., 2010. Are city logistics solutions sustainable? The Cityporto case. Territorio Mobilita`e Ambiente, 3(2), 55-64. (in Allen et al., 2012)

Goodchild, A., Wygonik, E., Keough, B., 2016. Deliver it all. Supply Chain Management Review, March/April, 20-26.

Hair, J.F., Black, W.C., Babin, B.J., Anderson, R.E., 2010. Multivariate data analysis: a global perspective. London: Pearson.

Higher Education Statistics Agency, 2015. Term-time accommodation of full-time undergraduate students. https://www.hesa.ac.uk/content/view/3313. Accessed 13 July 2016.

Hua, G., Wang, S., Cheng, T.C.E., 2010. Production, Manufacturing and Logistics: Price and lead time decisions in dual-channel supply chains. European Journal of Operational Research, 205, 113-126.

IMRG, 2015. Online retail parcel volumes exceed forecast in 2015. www.imrg.org/mediaand-comment/press-releases/online-retail-parcel-volumes-exceed-forecast-in-2015/. Accessed 10 January 2017.

Key Note, 2015. Courier and express services. Market Report, $19^{\text {th }}$ edition, May 2015 , ISBN 978-1-78304-291-3.

Kim, S., Park, H., 2013. Effects of various characteristics of social commerce (s-commerce) on consumers' trust and trust performance. International Journal of Information Management, 33, 318-332. 
Kin, B., Verlinde, S., van Lier, T., Macharis, C., 2016. Is there life after subsidy for an urban consolidation centre? An investigation of the total costs and benefits of a privately-initiated concept, Transportation Research Procedia, 12, 357-369.

Marcucci, E., Danielis, R., 2007. The potential demand for a urban freight consolidation centre. Transportation 35(2): 269-84. DOI: 10.1007/s11116-007-9147-3.

McKinnon, A., 1998. International review of urban transhipment studies and initiatives. Report prepared for the retail and distribution panel of the UK Government's Foresight Programme. Edinburgh: Heriot Watt University.

http://www2.hw.ac.uk/sml/downloads/logisticsresearchcentre/UKTranshipUK.pdf. Accessed 10 January 2017.

McKnight, D. H., Cummings, L. L., and Chervany, N. L., 1998. Initial trust formation in new organizational relationships. Academy of Management Review, 23, 473-490.

McLeod, F., Cherrett, T., Bailey, G, 2016. 'Shop and we'll drop' - Understanding the impacts of student e-shopping on deliveries to university halls of residence during Black Friday week. In: $21^{\text {st }}$ Annual Logistics Research Network Conference, Hull, UK.

Mintel, 2015a. Lifestyles of millennials: UK October 2015. London: Mintel Group Ltd. http://store.mintel.com/lifestyles-of-millennials-uk-october-2015. Accessed 10 January 2017.

Mintel, 2015b. The working life: UK December 2015. London: Mintel Group Ltd. http://store.mintel.com/the-working-life-uk-december-2015. Accessed 10 January 2017.

Mintel, 2015c. Online Retailing - UK - July 2015. London: Mintel Group Ltd. http://store.mintel.com/online-retailing-uk-july-2015. Accessed 10 January 2017.

Mintel, 2016. Attitudes towards home-delivery and takeaway food: UK April 2016. London: Mintel Group Ltd. http://store.mintel.com/attitudes-towards-home-delivery-and-takeawayfood-uk-april-2016. Accessed 10 January 2017.

Morganti, E., Dablanc, L., 2014. Recent innovation in last mile deliveries. In A. Hyard, Nontechnological Innovations for Sustainable Transport, 27-45.

OECD, 2003. Delivering the goods: $21^{\text {st }}$ century challenges to urban goods transport. Organisation for Economic Co-operation and Development (OECD), Paris, France. http://www.oecd-ilibrary.org/transport/delivering-the-goods 9789264102828-en. Accessed 26 August 2016.

Ofcom, 2015. The communications market report 2015. http://stakeholders.ofcom.org.uk/market-data-research/market-data/communications-marketreports/cmr15/. Accessed 14 September 2016.

Panero, M., Lopez, D., 2011. Urban Distribution Centres. A means to reducing freight vehicle miles travelled. Final report prepared for the New York State Research Development Authority. Albany, NY. https://www.dot.ny.gov/divisions/engineering/technical-services/transr-and-d-repository/C-08-23 0.pdf. Accessed 26 August 2016.

Park, J., Kim, J., 2007. The importance of perceived consumption delay in internet shopping: time-related information, time risk, attitude, and purchase intention. Clothing \& Textiles Research Journal, 25(1), 24-41 
Passport, 2013. The Millennial generation is ready to spend. London: Euromonitor International. Retrieved from http://www.portal.euromonitor.com/portal/analysis/tab. Accessed 10 January 2017.

Passport, 2015. Deconstructing the student lifestyle and student consumers: The Americans. London: Euromonitor International. http://www.portal.euromonitor.com/portal/analysis/tab. Accessed 10 January 2017.

People and Planet, 2015. University League 2015 tables.

http://peopleandplanet.org/university-league/2015/tables. Accessed 27 August 2016.

Rao, L., 2016. Black Friday online sales expected to hit a record $\$ 3$ billion. Fortune. Retrieved from http://fortune.com/2016/11/25/black-friday-online-sales/. Accessed 10 January 2017.

Retail Research, 2016. Online retailing: Britain, Europe, US and Canada 2016. http://www.retailresearch.org/onlineretailing.php. Accessed 21 August 2016.

Savelsbergh, M., Van Woensel, T., 2016. $50^{\text {th }}$ Anniversary Invited Article - City Logistics: Challenges and Opportunities, Transportation Science 50(2), 579-590.

Seock, Y.-K., Bailey, L.R., 2008. The influence of college students' shopping orientations and gender differences on online information searches and purchase behaviours, International Journal of Consumer Studies, 32, 113-121.

Shin, S., Lee, S., Aiken, K.D., Chaiy, S., 2016. "Made in" versus "Shipped from": Countryof-delivery-origin effects and the role of perceived risk. Journal of Internet Commerce, 11, 187-207. DOI: $\underline{10.1080 / 15332861.2012 .729462}$

ShopperVista, 2016. Online shopping trends 2016. Watford, UK: The Institute of Grocery Distribution website: http://shoppervista.igd.com/Hub.aspx?id=35\&tid=4\&rptid=368. Accessed 10 January 2017.

Sinha, P., Singh, S., 2014. Product characteristics vis-à-vis consumers' risk perception: A conceptual study of online shopping. The IUP Journal of Marketing Management, XIII(2), 4057.

Stanes, E., Klocker, N., Gibson, C., 2015. Young adult households and domestic sustainabilities. Geoforum, 65, 46-58.

Statista, 2016. How consumers best describe their shopping behaviour in the United Kingdom (UK) in 2014, by age group. Available at:

http://www.statista.com/statistics/320216/shopping-behaviour-in-the-united-kingdom-uk-byagel. Accessed 6 June 2016.

The Guardian, 2016. Deliveroo told it must pay workers minimum wage.

https://www.theguardian.com/society/2016/aug/14/deliveroo-told-it-must-pay-workersminimum-wage. Accessed 10 September 2016.

Thomas, J. B., Peters, C. (2011). An exploratory investigation of Black Friday consumption rituals. International Journal of Retail \& Distribution Management, 39, 522-537. DOI: $\underline{10.1108 / 09590551111144905}$ 
Torbianelli, V, 2009. Road congestion generated by distribution centres in European port regions: Risks and opportunities of the development of hybrid logistics. Pomorstvo - Journal of Maritime Studies, 23(1), 21-39.

Transport for London, 2016. Delivery and Servicing Plans. Making freight work for you. http://content.tfl.gov.uk/delivery-and-servicing-plans.pdf. Accessed 10 January 2017.

Triantafyllou, M., Cherrett, T., Browne, M, 2015. Urban freight consolidation centers: a case study in the UK retail sector. Trans. Res. Rec.: J of the Trans Res Bd. 2411, 34-44. DOI: $\underline{10.3141 / 2411-05 .}$

Universities UK Efficiency and Modernisation Task Group, 2011. Efficiency and effectiveness in higher education. http://www.universitiesuk.ac.uk/policy-andanalysis/reports/Documents/2011/ report-by-efficiency-and-modernisation-task-group.pdf. Accessed 27 August 2016.

UOS, 2016. Blackout. University of Southampton Sustainability Action Programme. http://www.southampton.ac.uk/sustainabilityaction/experience/blackout.page. Accessed 3 January 2017.

van Rooijen, T., Quak, H., 2010. Local impacts of a new urban consolidation centre - the case of Binnenstadservice.nl. Procedia - Social and Behavioral Sciences, 2, 5967-5979.

Verlinde, S., Macharis, C., Witlox, F., 2012. How to consolidate urban flows of goods without setting up an urban consolidation centre? Procedia - Social and Behavioral Sciences, 39, 687-701.

Vidotto G., Massidda D., Noventa S., Vicentini M., 2012. Trusting beliefs: A functional measurement study. Psicòlogica, 33(3): 575-590.

Veiga, A., 2016. Dialing up deals: Black Friday online sales hit new high. Daily Herald. http://search.ebscohost.com/login.aspx?direct=true\&db=edsgin\&AN=edsgcl.471925529\&site =eds-live\&scope=site. Accessed 10 January 2017.

Visser, J., Nemoto, T., and Browne, M., 2014. Home delivery and the impacts on urban freight transport: a review. Procedia - Social and Behavioral Sciences, 125, 15-27.

Wells, P., Bristow, G., Nieuwenhuis, P., Christensen, T.B., 2009. The role of academia in regional sustainability initiatives: Wales. Journal of Cleaner Production, 17(12), 1116-1122.

Wiese, A., Zielke, S., Toporowski, W, 2015. Shopping travel behaviour: Influencing factors, shopper types and environmental consequences. International Journal of Retail \& Distribution Management, 43(4/5).

Wenig, D., London, S., 2014. How digital is transforming retail: The view from eBay. McKinsey \& Company website: http://www.mckinsey.com/industries/retail/our-insights/howdigital-is-transforming-retail-the-view-from-ebay. Accessed 10 January 2017.

WSP, 2008. Freight consolidation and remote storage. London: BCSC Educational Trust. https://www.bcsc.org.uk/documents/get lob?id=122\&age=\&field=file. Accessed 26 August 2016.

Zimbado, P.G., Boyd, J.N., 1999. Putting time in perspective: a valid, reliable individualdifferences metric. Journal of Personality and Social Psychology. 77(6), 1271-1288. 
Zunder, T. H., Marinov, M. V., 2011. Urban freight concepts and practice: would a traditional UCC scheme work? Transport Problems, 6(1).

Zunder, T.H., Aditjandra, P.T. and Carnaby, B., 2014. Developing a local research strategy for city logistics on an academic campus. International Journal of Urban Sciences, 18(2), 262-277. 